\title{
O BRINCAR EM TEMPOS DE DISTANCIAMENTO SOCIAL: 0 QUE APRENDEMOS COM AS CRIANCAS PELA LENTE DA SOCIOLOGIA DA INFÂNCIA?
}

\author{
PLAYING IN TIMES OF SOCIAL DISTANCING: WHAT WE LEARN WITH CHILDREN \\ THROUGH THE LENS OF SOCIOLOGY OF CHILDHOOD?
}

JUGAR EN TIEMPOS DE DISTANCIAMENTO SOCIAL: ¿LO QUE APRENDEMOS
CON LOS NIÑOS POR LAS LENTES DE LA SOCIOLOGIA DE LA INFANCIA?

Samantha Dias de Lima*

(1) http://orcid.org/oooo-0oo2-4597-5608

Melina C. Benincasa Meirelles**

(1.) https://orcid.org/oooo-ooo1-5365-185X

\begin{abstract}
REVISTA PEDAGÓGICA
Revista do Programa de Pós-graduação em Educação da Unochapecó | ISSN 1984-1566 Universidade Comunitária da Região de Chapecó | Chapecó-SC, Brasil Como referenciar este artigo: LIMA, S. D.; MEIRELLES, M. C. B. O brincar em tempos de distanciamento social: o que aprendemos com as crianças pela lente da sociologia da infância?. Revista Pedagógica, Chapecó, v. 22, p. 1-21, 2020. DOI: https://doi.org/10.22196/rp.v22io.5799
\end{abstract}

RESUMO: O presente artigo trata de uma pesquisa com crianças realizada neste momento de pandemia por pesquisadoras de um curso de Licenciatura em Pedagogia na Região da Serra Gaúcha/RS. Valendo-se das lentes da Sociologia da Infância, objetivou acolher e visibilizar, através de narrativas escritas, o que crianças entre seis e doze anos estão vivendo e sentindo nestes tempos de distanciamento sobre o brincar, convidando-as para que respondessem à seguinte pergunta: conte sobre as suas brincadeiras nestes tempos de distanciamento social, em que você está em casa. O convite foi feito via redes sociais institucionais do curso e obteve respostas de treze crianças por e-mail, WhatsApp e Instagram. Como resultados, a pesquisa deixa como legado essa consciência de cuidados consigo e com os outros expressos pelas crianças, bem como a percepção, considerando suas narrativas, de que o tempo do brincar, seja ele livre, com a família ou mesmo de modo contemplativo.

Palavras-chave: Sociologia da Infância. Brincar. Pesquisa com crianças. Narrativas escritas. Distanciamento social.

ABSTRACT: This paper reports a research with children conducted at this moment of pandemic by researchers of an Education undergraduate course in the Region of Serra Gaúcha/RS. Using the lenses of the Sociology of Childhood, it aimed to value and make visible, through written narratives, what children who are between six and twelve years old are living and feeling in these times of distancing regarding playing, inviting them to answer the following question: tell us about your games in these times of social distancing, in which you are staying home. The invitation was made through institutional social networks of the course and got answers from thirteen children by email, WhatsApp and Instagram. As results, the research leaves as legacy this conscience of self-care and caring for others expressed by the children, as well as the perception, considering their narratives, of the fact that the time of playing, be it free, with the family or even in a contemplative way.

Keywords: Sociology of Childhood. Playing. Research with children. Written narratives. Social distancing.

RESUMEN: Este artículo se ocupa de una investigación con los niños conducida en este momento de pandemia por investigadoras de un curso de Graduación en Pedagogía en la región de la Serra Gaúcha/RS. Usando las lentes de la Sociología de la Infancia, el artículo tuvo como objetivo apreciar y visibilizar, a través de narrativas escritas, lo que niños entre seis y doce años están viviendo y sintiendo en esta época de distanciamiento cuanto a jugar, invitándolos a contestaren a la pregunta siguiente: cuente sobre sus juegos en esta época de distanciamiento social, en que usted está en casa. La invitación fue hecha por las redes sociales institucionales del curso y obtuvo las respuestas de trece niños por e-mail, WhatsApp e Instagram. Como resultados, la investigación deja como herencia esta conciencia de cuidados consigo mismo y con el otro, expresos por los niños, así como la percepción, en vista de sus narrativas, de que el tiempo de jugar, ya sea libre, con la familia o mismo de modo contemplativo.

Palabras-clave: Sociología de la Infancia. Jugar. Investigación con niños. Narrativas escritas. 


\section{Notas introdutórias}

[...] o estudo das crianças a partir de si mesmas permite descortinar uma outra realidade social, que é aquela que emerge das interpretações infantis dos respectivos mundos de vida. O olhar das crianças permite revelar fenômenos sociais que o olhar dos adultos deixa na penumbra ou obscurece totalmente. (PINTO; SARMENTO, 1997, p.27).

O presente artigo busca dar visibilidade às crianças "a partir de si mesmas", tal como escrevem Pinto e Sarmento (1997) na epígrafe que abre este texto. Propõe um espaço de visibilidade e acolhimento às crianças com o objetivo de conhecer, através das suas narrativas escritas, o lugar que o brincar e as brincadeiras têm ocupado em suas vidas nestes tempos de distanciamento social, consequência da pandemia do coronavírus ${ }^{1}$.

A pesquisa é oriunda de um Projeto Indissociável, com ações voltadas ao ensino, à pesquisa e à extensão, vinculado à Brinquedoteca de um Curso de Licenciatura em Pedagogia de uma instituição pública de ensino, na Região da Serra Gaúcha/Rio Grande do Sul. Trata-se de uma pesquisa com crianças, mesmo que inicialmente tenha sido mobilizada com os adultos responsáveis por elas, em virtude do momento pandêmico em que nos encontramos, onde não é possível mantermos contato físico - o que exigiu novas formas de contatar as crianças. Ainda assim, a pesquisa mantém a sua filiação à Sociologia da Infância (SI) ao garantir a participação das crianças como protagonistas qualificadas.

Para a produção dos dados, convidamos crianças de seis a doze anos a contarem sobre as brincadeiras neste momento, através da seguinte pergunta: "conte sobre as suas brincadeiras nestes tempos de distanciamento social, em que você está em casa”. Deste modo, valendo-se da SI, a pesquisa foi desenvolvida mediante o recebimento de narrativas escritas pelas crianças participantes. Tais dados foram recebidos de diferentes modos, possibilitando uma variedade de interações digitais entre as pesquisadoras e as famílias - crianças e responsáveis -, tanto pelo e-mail institucional como por WhatsApp ou perfil do Instagram. Tais ferramentas digitais têm sido mobilizadas pelas pesquisadoras desde março de 2020, conforme descrevem na recente publicação intitulada Tecnologias Digitais de Informação e Comunicação como estratégia pedagógica: um olhar sobre a experiência de um curso de Pedagogia em tempos de pandemia. (LIMA; MEIRELLES, 2020).

Elegemos a lente da Sociologia da Infância para sustentar tal investigação por assumi-la enquanto princípio teórico, metodológico e analítico, que permite entender as crianças e suas infâncias por si mesmas, permitindo esca-

\begin{abstract}
* Pós-Doutora em Educação (Unisinos) e Doutora em Educação (UFRGS). Docente do Instituto Federal de Educação, Ciência e Tecnologia do Rio Grande do Sul - Campus Farroupilha. É líder do Grupo de Pesquisa em Docências na Educação Básica (Gpedeb/IFRS/CNPq) e integrante do Grupo Interinstitucional de Pesquisa em Docências, Pedagogias e Diferenças (GIPEDI/Unisinos/CNPq).

E-mail: samanthalimao6@gmail.com
\end{abstract}

** Doutora e Mestre em Educação pela UFRGS. Professora e Coordenadora do Curso de Licenciatura em Pedagogia no Instituto Federal de Educação, Ciência e Tecnologia do Rio Grande do Sul - Campus Farroupilha. Integrante do Núcleo de Estudos em Políticas de Inclusão Escolar (NEPIE/UFRGS) e do Grupo de Pesquisa em Docências na Educação Básica (Gpedeb/IFRS/CNPq).

E-mail: melina.benincasa@farroupilha. ifrs.edu.br

1 Trata-se de uma família de vírus que causam, principalmente, infecções respiratórias e provoca a doença chamada de Coronavírus ou Covid-19. Disponível em: www.coronavirus.saude.gov.br. 
par de imagens cristalizadas de inocência, pureza, incompletude e incompetência, por vezes associadas a elas. Analisar/refletir sobre como as crianças têm vivenciado seus modos de brincar em tempos de pandemia pela lente da SI exige um olhar renovado para as crianças e suas infâncias, reconhecendo-as enquanto fenômeno social, uma vez que elas participam da vida em sociedade, estando implicadas nas suas problemáticas. "Considerar que as crianças têm uma visão consistente, e própria, do mundo que as rodeia alerta-nos para a prioridade metodológica de lhes dar voz (na investigação) e as considerar informadoras credíveis sobre as suas vidas e os significados que lhes atribuem". (ALMEIDA, 2009, p. 34).

O texto tem como objetivos acolher $e$ visibilizar, por meio de narrativas escritas, o que as crianças estão vivendo e sentindo nestes tempos de distanciamento social sobre o brincar, uma vez que, no Brasil, as instituições educativas estão fechadas desde a segunda quinzena de março de 2020, bem como outros espaços coletivos de convivência, como clubes, parques, praças, shoppings, teatros, cinemas, entre outros.

Neste sentido, enquanto pesquisadoras que se dedicam às infâncias, interessa-nos muito conhecer como as crianças estão brincando, incluindo seus tempos e modos de brincar, pois defendemos que

O brincar é uma ação livre, que surge a qualquer hora, iniciada e conduzida pela criança, dá prazer, não exige, como condição um produto final, relaxa, envolve, ensina regras, linguagens desenvolve habilidade e introduz no mundo imaginário. (KISHIMOTO, 2010, p. 90).

Partindo da centralidade que o brincar ocupa na vida da criança e buscando conhecer como isso está acontecendo neste momento de distanciamento social, organizamos o texto em duas seções. Na primeira, Pesquisa com crianças: um olhar renovado da Sociologia da Infância, buscamos mostrar o investimento que a Sociologia da Infância tem feito nos modos de reconhecimento e visibilidade das crianças e das suas infâncias, bem como o protagonismo da criança nesse contexto teórico-metodológico de fazer pesquisa. Na segunda seção, Vamos Brincar? O que narram as crianças em tempos de distanciamento social, apresentamos os dados produzimos pelas crianças nesta pesquisa.

\section{Pesquisa com crianças: um olhar renovado da sociologia da infância}

A Sociologia da Infância propõe-se a constituir a infância como objecto sociológico, 
resgatando-a das perspectivas biologistas, que a reduzem a um estado intermédio de maturação e desenvolvimento humano, e psicologizantes, que tendem a interpretar as crianças como indivíduos que se desenvolvem independentemente da construção social das suas condições de existência e das representações e imagens historicamente construídas sobre e para eles. Porém, mais do que isso, a sociologia da infância propõe-se a interrogar a sociedade a partir de um ponto de vista que toma as crianças como objecto de investigação sociológica por direito próprio, fazendo acrescer o conhecimento, não apenas sobre infância, mas sobre o conjunto da sociedade globalmente considerada. (SARMENTO, 2005, p. 361).

Olharmos para as crianças e para as suas infâncias através da lente da Sociologia da Infância é algo muito potente. Reconhecer que elas compõem um grupo social de caráter permanente faz com seja possível investigar suas problemáticas pelo seu próprio mérito. Neste sentido, a Sociologia da Infância é uma área de estudo relativamente nova e, em alguns momentos, é considerada até complexa de ser compreendida por alguns. Tal área estuda as infâncias não apenas para compreendê-las, mas para entender a sociedade contemporânea também pelo olhar legítimo das crianças. Conforme escrito por Sarmento (2009), a SI não se preocupa exclusivamente com as crianças; pelo contrário, busca compreender a sociedade a partir de um novo objeto de estudo - o fenômeno social da infância.

É por isso que, na verdade, ao estudar a infância, não é apenas com as crianças que a disciplina se ocupa: é, com efeito, a totalidade da realidade social o que ocupa a Sociologia da Infância. Que as crianças constituem uma porta de entrada fundamental para a compreensão dessa realidade é o que é, porventura, novo e inesperado no desenvolvimento recente da disciplina. (SARMENTO, 2009, p. 19).

Conhecer o que pensam as crianças através da lente da Sociologia da Infância faz com que possamos desenvolver estudos com as crianças, que têm diferentes modos de viver suas infâncias, rompendo com visões uniformes do que venha a ser essa etapa da vida.

A infância é mais que uma fase de transição; é uma categoria social permanente. Independentemente das crianças que compõem a infância em determinado momento e lugar, 
a infância continua existindo, bem como o aparato regulatório e institucional que está ao seu redor. (LIMA, 2018, p. 25).

Nessa direção, as crianças e suas infâncias são postas no centro desta pesquisa, enquanto atores sociais. Há de se reconhecer que elas compõem um grupo social, apesar de, em alguns momentos históricos, terem sido invisibilizadas pelos adultos. Para Fernandes, as crianças:

[...] têm um espaço e tempo que, apesar das especificidades culturais, sociais, econômicas, configuradoras de complexidades e dissemelhanças significativas entre os seus elementos, marcam uma etapa de vida para qualquer indivíduo, e determinam também a organização de qualquer sociedade. (FERNANDES, 2009, p. 25 - grifos nossos).

Atualmente, a sociedade está passando por algo semelhante ao descrito por Fernandes (2009), pois, com a pandemia mundial de Covid-19 e o consequente fechamento dos espaços coletivos frequentados pelas crianças, suas famílias se tornaram, na maioria das situações, responsáveis pelos cuidados e pela educação em tempo integral. Isso impacta nos modos de vida, pois as crianças não são imunes aos regimes das suas sociedades; e consequentemente nos modos de pensar/fazer pesquisa, não só com crianças - assunto que desenvolvemos na seção seguinte.

Cabe pontuarmos que a mudança de paradigma relativa ao reconhecimento da infância enquanto uma categoria própria, para além dos aspectos biológicos e psicologizantes, está entre as mudanças mais significativas ocorridas nesse campo nos últimos anos; e os Estudos das Infâncias ${ }^{2}$, enquanto conjunto de investimentos, contribuíram significativamente para isso. "A investigação na infância, julgando processos em que as crianças são consideradas atores, com um papel mais ou menos ativo, mas sempre importante no conhecimento que se constrói acerca delas”. (FERNANDES, 2016, p. 761).

Realizar uma pesquisa com crianças pelo viés da Sociologia Infância tem implicações éticas e metodológicas. Em nossa investigação, procuramos desenvolver tanto os cuidados éticos quanto as estratégias metodológicas que nos permitissem considerar as crianças como partícipes da investigação, de maneira que elas se sentissem parceiras e valorizadas no percurso da pesquisa.

Ainda segundo Fernandes (2016), renovar as estratégias metodológicas

[...] não significa uma rejeição do conhecimento tradicional e dos métodos utilizados
2 Os Estudos da Infância e os Estudos da Criança são compreendidos como campos de intersecção entre disciplinas e questionamentos sobre as características ou os atributos da infância nos distintos momentos vividos nos anos iniciais da vida, embora saibamos que essas etapas não são estáveis, e suas representações mudam no tempo e no espaço. (BARBOSA; DELGADO; TOMÁS, 2016, p. 107). 
em pesquisa ao longo dos tempos, mas sim que se considerem novas possibilidades de aceder metodologicamente às crianças, como informantes, o que implica mobilizar novos posicionamentos metodológicos e éticos respeitadores das especificidades de que se reveste a investigação come esse grupo. (FERNANDES, 2016, p. 763).

As crianças são eticamente investigadas quando ocupam centralidade no processo investigativo. Tal processo deve documentar, analisar, avaliar e interpretar os dados produzidos, uma vez que, ao investigar algum fenômeno relativo às crianças e às suas infâncias - nesta pesquisa, o brincar em tempos de pandemia -, devemos considerar alcançar, além dos interesses de pesquisa, os interesses das crianças. Desse modo, é preciso questionar que impactos a investigação tem na vida das crianças e encará-las como atores sociais competentes.

Desenvolver uma pesquisa eticamente comprometida com as crianças faz com que tenhamos de criar novos dispositivos para que elas se assumam como protagonistas. Nesta pesquisa, esse vínculo se deu por meio das tecnologias digitais, que iremos detalhar na próxima seção.

Contudo, ainda que estejamos comprometidas com a SI como viés teórico, metodológico e analítico, isso não representa votos de imparcialidade no fazer da pesquisa, mas implica nossa atenção com o objeto de estudo, para que não se perca o foco, tampouco a visão sociológica. Neste sentido,

[...] não há procedimentos técnico-metodológicos neutros, contudo defende que para não cairmos no erro de demonstrar apenas o que se pretende e quer encontrar, é importante promover o ecletismo na utilização de instrumentos e técnicas de recolha de dados e promover a integração da teoria na reflexão metodológica. (TOMÁS, 2011, p. 146).

Ainda que o texto tenha sua escrita marcada pela lente da Sociologia da Infância, em alguns momentos, torna-se complexo escrever sobre as infâncias, considerando a existência de outras visões e outras vozes sobre as crianças, considerando os investimentos da área dos Estudos da Infância. Mas isso não se configura em desordem, pelo contrário, é reflexo dos investimentos que a área tem recebido nos últimos anos. Desta forma, nossa investigação ganha também um status exploratório, uma vez que "[...] o conhecimento científico que tem vindo a ser construído, no sentido de problematizar e criticamente entender o exercício de direitos para as crianças, permite-nos desvendar 
aspectos como a reflexão acerca da legitimidade social e científica sobre as reivindicações das crianças". (FERNANDES, 2009, p. 29).

\section{Caminhos metodológicos}

Neste espaço do texto nos dedicamos a apresentar nossas escolhas metodológicas, que estão intimamente vinculadas com a nossa forma de conceber as infâncias. Assim, como vistas de atingir o objetivo do estudo, escolhemos produzir os dados por meio de narrativas escritas pelas crianças participantes. Conforme Bruner (2002), a linguagem oral, especialmente a narrativa, impõe um ponto de vista não apenas sobre o mundo ao qual ela se refere, mas também sobre a sua relação com esse mundo. Dito isso, a escolha pelo aporte das narrativas escritas se deu por considerarmos que se trata de uma potente ferramenta que alia princípios metodológicos e investigativos, valorizando a participação das crianças e de suas linguagens como processo, e não apenas como produção final. "As narrativas, como princípio metodológico-investigativo, investigam justamente perceber no discurso do outro a possibilidade de dados significativos, que colaborem com a pesquisa em um determinado contexto". (LIMA, 2017, p. 245).

Por se tratar de uma pesquisa com crianças, ainda que inicialmente mobilizada por adultos, houve uma série de cuidados éticos e metodológicos, considerando o contexto de distanciamento social que estamos vivenciando. $\mathrm{O}$ convite para participação se deu por meio do perfil institucional do Instagram e de grupos de WhatsApp das pesquisadoras envolvidas. O convite foi dirigido, no primeiro momento (figura 1), aos adultos que tinham crianças em casa. Os momentos de contato direcionados primeiramente aos adultos, entendendo-os como "facilitadores", partindo da descrição de Fernandes, "[...] foram importantíssimos para o desenvolvimento da investigação, nomeadamente no que diz respeito à disponibilidade de tempos e espaços para as crianças e investigadora (s) poder (em) trabalhar". (FERNANDES, 2009, p. 135 - acréscimos nossos).

No segundo momento (figura 2), tínhamos um material para ser entregue às crianças, sendo fundamental a colaboração dos facilitadores para fazer chegar às suas "mãos" o chamamento para a pesquisa, o qual solicitava que compartilhassem suas narrativas sobre o brincar em tempos de distanciamento social, estimulando-as que nos contassem sobre suas brincadeiras nestes tempos de pandemia, em que se encontram em casa e afastadas do espaço escolar físico. Fizemos questão de sublinhar que suas narrativas escritas poderiam ser feitas de forma livre, produzidas por elas conforme seu desejo e condições de escrita, 
não havendo necessidade de que os familiares responsáveis redigissem ou efetuassem quaisquer correções no texto que seria enviado para nós. Cada narrativa recebida teve o nosso agradecimento e o nosso compromisso de enviar este texto, quando publicado.

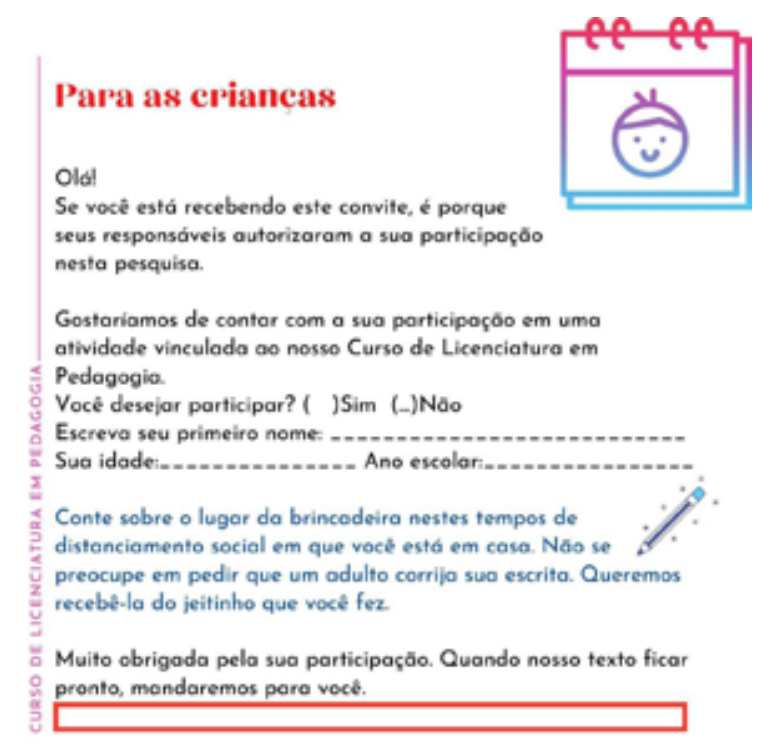

Figura 1 - Convite aos adultos.

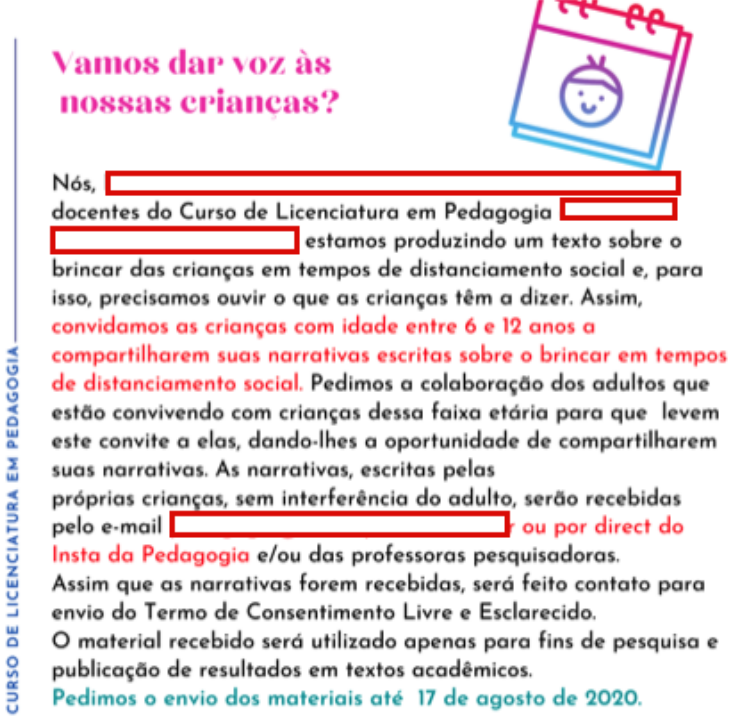

Figura 2 - Convite às crianças.

Deste modo, também justificamos o critério de participação, que convidou crianças com idades entre de seis a doze anos que já estivessem alfabetizadas para realizarem sua escrita espontânea sem a interferência do adulto.

A escolha por uma pesquisa realizada de forma não presencial (virtual) deu-se pelo fato de estarmos diante de um momento complexo e delicado, no qual o distancia- 
mento social faz-se necessário, assegurando assim a participação das crianças de maneira segura. Todas as narrativas foram recebidas de forma virtual, por três canais de comunicação: e-mail institucional, perfil do Instagram e WhatsApp das pesquisadoras envolvidas no estudo.

Após o aceite para participar da pesquisa por parte das crianças, os responsáveis receberam um Termo de Consentimento Livre e Esclarecido (TCLE), onde foram tratadas com os facilitadores as questões de ética na pesquisa com seres humanos, seguindo as orientações constantes na Resolução n. 510/2016 do Conselho Nacional de Saúde (BRASIL, 2016). Os participantes tiveram ciência e concordância com o TCLE, que deveria ser enviado juntamente com a narrativa às pesquisadoras, e os lembramos sempre do direito ao anonimato de todos os participantes da pesquisa. Observamos que, ao longo deste artigo, nomearemos os participantes pelo termo Criança, seguido da numeração de recebimento e de sua idade.

Lançado o convite nas redes sociais e grupos de WhatsApp das pesquisadoras, obtivemos o retorno de 13 narrativas, sendo nove de meninas e quatro de meninos com idades entre seis e doze anos. Mais especificamente, contamos com a participação de duas crianças de seis anos, duas meninas de oito anos, três crianças de nove anos, um menino de dez anos, duas crianças de onze anos e três de doze anos de idade. No que tange à forma da escrita, onze crianças enviaram as narrativas escritas de próprio punho, e duas, de forma digital, escritas no computador. Além disso, duas narrativas foram escritas pelos responsáveis, visto que eram crianças de seis anos de idade e que ainda se encontram em processo de alfabetização. Como nossa abordagem inicial foi dirigida aos adultos responsáveis pelas crianças, tivemos uma certa dificuldade em receber os retornos, pois os adultos estão em home office e com uma série de demandas do cotidiano familiar - do mesmo modo que as crianças, as quais, neste momento, encontram-se sobrecarregadas com uma série de atividades escolares online/virtuais.

No que diz respeito ao tempo de envio por parte dos participantes, houve um período de 40 dias de chamadas nas redes sociais para a participação na pesquisa. Acreditamos que, apesar desses dias disponíveis para o recebimento das narrativas e dos TCLE, essas novas dinâmicas da vida familiar, em que as famílias estão conciliando trabalho doméstico, cotidiano profissional e atividades escolares, tenha faltado tempo e/ou incentivo para a participação das crianças. Isso fez com que a ideia inicial de uma pesquisa com crianças, ainda que mediada por adultos, não encontrasse o tempo-espaço desejado, ou seja, aquele que visa a ofertar a participação ativa das crianças e um dos direitos 
básicos do ser humano: o de expressar sua opinião, de ser escutado, conforme assegurado no Artigo 12 da Convenção sobre os Direitos das Crianças ${ }^{3}$ (BRASIL, 1990).

Do ponto de vista metodológico, tendo em mãos o material produzido pelas crianças, perguntamo-nos: e agora? Como efetuar uma leitura respeitosa e eticamente comprometida da escrita dessas crianças, que, como muitas outras, estão vivenciando um momento histórico que assola não apenas sua cidade, seu país, mas também o mundo inteiro? De que modos podemos operar com a lente da Sociologia da Infância na visibilidade das crianças a partir de suas narrativas?

\section{Vamos brincar? $O$ que narram as crianças em tempos de distanciamento social}

Partindo das questões que encerraram a seção anterior, iremos a partir deste momento, nos dedicar a apresentar os dados construídos na pesquisa com as crianças através da participação por meio do envio das suas narrativas escritas. Associamo-nos a Fernandes quando diz que

[...] a expressão infantil, que é a manifestação do ser, pensar e sentir das crianças. Este ser, pensar e sentir deverão estar em correspondência com os seus interesses, mas não são também reflexo das influências que a criança sente da parte dos pais, professores, meios de comunicação social, revelando, portanto, diferentes graus de autenticidade. (FERNANDES, 2009, p.100).

Tomamos a escrita das crianças como sua "expressão infantil"; e, nas narrativas, percebemos essas manifestações do pensar, do sentir e das influências do mundo em que se encontram. Por isso, também enxergamos nossa pesquisa como algo exploratório, pois nunca essas crianças viveram tal situação: estar longe da escola, dos amigos e da rotina que tinham antes de iniciar a pandemia, no mês de março, tem impactado seus modos de vida.

Com o intuito de situar o leitor acerca das crianças participantes, a tabela a seguir apresenta a sua caracterização, considerando suas idades, gênero e formato da escrita do material recebido.
3 Documento do qual Brasil foi signatário em setembro de 1990. 
Tabela 1 - Caracterização das crianças participantes

\begin{tabular}{cccc}
\hline Criança & Idade & Sexo $^{4}$ & Tipo de escrita \\
\hline Criança 1 & 06 & $\mathrm{M}$ & Digitada pelo pai \\
Criança 2 & 06 & $\mathrm{~F}$ & Digitada pela mãe \\
Criança 3 & 08 & $\mathrm{~F}$ & Escrita a mão \\
Criança 4 & 08 & $\mathrm{~F}$ & Escrita a mão \\
Criança 5 & 09 & $\mathrm{~F}$ & Escrita a mão \\
Criança 6 & 09 & $\mathrm{~F}$ & Escrita a mão \\
Criança 7 & 09 & $\mathrm{~F}$ & Escrita a mão \\
Criança8 & 09 & $\mathrm{M}$ & Escrita a mão \\
Criança 9 & 10 & $\mathrm{M}$ & Escrita a mão \\
Criança 10 & 11 & $\mathrm{~F}$ & Escrita a mão \\
Criança 11 & 12 & $\mathrm{~F}$ & Escrita a mão \\
Criança 12 & 12 & $\mathrm{~F}$ & Escrita digital \\
Criança 13 & 12 & $\mathrm{M}$ & Escrita a mão \\
\hline
\end{tabular}

Fonte: Elaborado pelas autoras (2020).

As narrativas das duas crianças de seis anos chegaram a nós por meio das escritas realizadas pelos responsáveis. Apesar de, nas figuras 1 e 2, estar sinalizado no convite que a escrita deveria ser realizada pelas crianças, mantivemos a inserção delas na pesquisa, por representarem a faixa etária de seis anos e por compreendermos que, neste momento, por falta de acesso à escola física, os seus processos de alfabetização também estão sendo afetados. Tê-las na pesquisa é uma forma de visibilizá-las, um dos nossos objetivos.

Após a caracterização das participantes, gostaríamos de iniciar nossos movimentos com os materiais recebidos. Cabe registrar o quão complexo é

[...] escrever sobre a infância é necessário lê-la e compreendê-la, mesmo que muitas vezes ela se mostre, a primeira abordagem, ilegível, incompreensível, talvez até inacessível. Escrever sobre a infância é, afinal, uma tentativa de mapear a multiplicidade dos sentidos, as múltiplas vozes e as diferentes escalas onde as crianças se movem e são movidas. (TOMÁS, 2011, p. 134 - grifos nossos).

E foi isso que fizemos, "lemos as crianças" a partir das suas narrativas escritas, buscando, através dos seus escritos, compreender também as mudanças das infâncias com relação ao brincar nestes últimos meses. Afinal, o brincar é um direito "garantido" da criança, expresso tanto no Artigo 31 da Convenção sobre os Direitos das Crianças (BRASIL, 1990) quanto nos Artigos 4 e 16 do Estatuto da Criança e
4 Utilizaremos M para sinalizar o sexo masculino e F para o feminino. 
do Adolescente (1990) - embora esse direito ainda não seja exercido plenamente por todas elas.

Quando iniciamos esta investigação, perguntávamo-nos: como está se dando o brincar das crianças em tempos de pandemia? Questionávamo-nos se suas brincadeiras, principalmente seus tempos e espaços de brincar, estavam sendo afetados pela triste realidade que o mundo está enfrentando com a pandemia de Covid-19. Para responder a essa pergunta e socializar os dados produzidos, organizamos a tabela 2, na qual apresentamos uma visão panorâmica das narrativas recebidas.

Tabela 2 - Sistematização das brincadeiras.

\begin{tabular}{|c|c|c|c|c|}
\hline $\begin{array}{l}\text { Identificação } \\
\text { da criança } \\
\text { participante }\end{array}$ & $\begin{array}{l}\text { Brinquedos e } \\
\text { brincadeiras }\end{array}$ & $\begin{array}{l}\text { Relação com as } \\
\text { tecnologias }\end{array}$ & $\begin{array}{l}\text { Brinca com } \\
\text { quem? }\end{array}$ & $\begin{array}{l}\text { Menção à } \\
\text { pandemia }\end{array}$ \\
\hline Criança 1 & $\begin{array}{c}\text { Brinca de pega-pega, } \\
\text { esconde-esconde e com bola. }\end{array}$ & Assiste televisão. & $\begin{array}{l}\text { Com o } \\
\text { cachorro. }\end{array}$ & ---5 \\
\hline Criança 2 & $\begin{array}{l}\text { Montar dinossauro e lego. Confeccionou } \\
\text { brinquedos e brinca no pátio. }\end{array}$ & $\begin{array}{l}\text { Assiste vídeos no } \\
\text { YouTube }\end{array}$ & --- & --- \\
\hline Criança 3 & $\begin{array}{l}\text { Brinca de pega-pega, esconde-esconde, } \\
\text { cabra-cega e com bola. }\end{array}$ & --- & $\begin{array}{l}\text { Com o } \\
\text { cachorro. }\end{array}$ & --- \\
\hline Criança 4 & $\begin{array}{l}\text { Brinca com boneca, lê gibi, } \\
\text { desenha e escreve. }\end{array}$ & --- & $\begin{array}{l}\text { Brinca com } \\
\text { vizinha e } \\
\text { amigo. }\end{array}$ & Sim \\
\hline Criança 5 & $\begin{array}{l}\text { Brinca de boneca e de cozinha, } \\
\text { com jogos e com tinta. }\end{array}$ & --- & Com a irmã. & --- \\
\hline Criança 6 & $\begin{array}{l}\text { Brinca com slime, de cozinha, } \\
\text { gosta de ler, brincar de escritório, } \\
\text { desenhar e se maquiar. }\end{array}$ & $\begin{array}{l}\text { Joga no celular e } \\
\text { assiste vídeos. }\end{array}$ & Com o coelho. & --- \\
\hline Criança 7 & Boneca, patinete & --- & Sozinha & Sim \\
\hline Criança 8 & Joga futebol, pife, basquete. & Joga videogame & Com os irmãos. & Sim \\
\hline Criança 9 & --- & --- & --- & Sim \\
\hline Criança 10 & $\begin{array}{l}\text { Brinca dentro de casa com } \\
\text { os próprios brinquedos. }\end{array}$ & --- & Sozinha & Sim \\
\hline Criança 11 & Pintura, culinária, dança e canta. & -- & Com a irmã. & Sim \\
\hline Criança 12 & $\begin{array}{l}\text { Brincar dentro de casa e } \\
\text { no pátio de corda, dança. }\end{array}$ & $\begin{array}{l}\text { Ligação de } \\
\text { videochamada com a } \\
\text { família. }\end{array}$ & $\begin{array}{l}\text { Com o } \\
\text { cachorro. }\end{array}$ & Sim \\
\hline Criança 13 & $\begin{array}{l}\text { Jogar futebol, basquete, } \\
\text { dardo, anda de bicicleta. }\end{array}$ & $\begin{array}{c}\text { Joga videogame, } \\
\text { assiste televisão, mexe } \\
\text { no celular e posta } \\
\text { vídeos no seu canal do } \\
\text { YouTube. }\end{array}$ & $\begin{array}{l}\text { Brinca com a } \\
\text { família, com o } \\
\text { irmão e com o } \\
\text { cachorro. }\end{array}$ & --- \\
\hline
\end{tabular}

Fonte: Elaborado pelas autoras (2020).

Conforme podemos observar na tabela anterior, percebemos que as crianças estão brincando em casa no seu contexto familiar. As tecnologias e as brincadeiras tidas como tradicionais dividem a atenção das participantes, enquanto a menção à pandemia aparece na expressão de

5 Optamos por usar esse símbolo quando a criança não menciona nada sobre o referido item na sua narrativa. 
cuidados com a higiene, com destaque para a importância do distanciamento social, relacionando a doença com um "machucado que irá se curar" (Criança 9). Para aprofundarmos as análises acerca das brincadeiras em tempos de pandemia, organizamos dois grupos de sentidos a partir das recorrências encontradas nas narrativas. O primeiro se intitula "Eu brinco quando dá": sentidos do brincar pelas crianças, que retrata a complexidade dessa atividade tão presente na sua vida, e que neste momento precisou ser adaptada para atender aos novos protocolos da vida cotidiana. E o segundo grupo de sentido é denominado "Vai passar": dilemas contemporâneos das crianças, que apresenta alguns desses dilemas acentuados com a pandemia, como brincar sozinho, brincar em casa e dentro das possibilidades disponíveis neste momento.

\section{“Eu brinco quando dá": sentidos do brincar pelas crianças}

Nessa quarentena, minhas brincadeiras são só dentro de casa e no pátio. Amo desenhar e dançar. Acho que nessa quarentena o mais dificil é saber do que brincar, como se distrair, já que faz tanto tempo q estou em casa, mas um pouco de criatividade ajuda! (CRIANÇA 12 - grifos nossos)

Partindo do excerto da narrativa da Criança 12, percebemos que o ato de brincar está atravessado por múltiplas questões. Muitas vezes, acreditamos de modo naturalizado que, quando as crianças estão em casa, elas brincam mais. Mas, neste momento pandêmico, em que estão em casa há mais de cinco meses ${ }^{6}$, as crianças sinalizam inclusive dificuldades de "saber do que brincar", considerando as análises das narrativas. Aquele brincar enquanto espaço de possibilidade, de aprendizado, e até mesmo de aventura, ganha novos sentidos nos tempos atuais. Como bem destaca Huizinga, "[...] a brincadeira comprime e solta; a brincadeira arrebata, eletriza, enfeitiça. Está cheia das duas qualidades mais nobres que o homem pode encontrar nas coisas e expressá-las: ritmo e harmonia." (HUIZINGA, 1987, p. 23). Neste sentido, perguntamo-nos o quanto $\mathrm{o}$ ato do brincar será ressignificado no momento em que as crianças retornarem às escolas ou a outros espaços que permitam novamente outros contatos sociais.

Elas sinalizam, além da dificuldade de "saber do que brincar”, sentimentos como preguiça e cansaço, conforme mostramos com as próximas duas narrativas.
$6 \mathrm{O}$ texto foi finalizado em agosto/2020, e o distanciamento social das crianças iniciou em março do mesmo ano. 


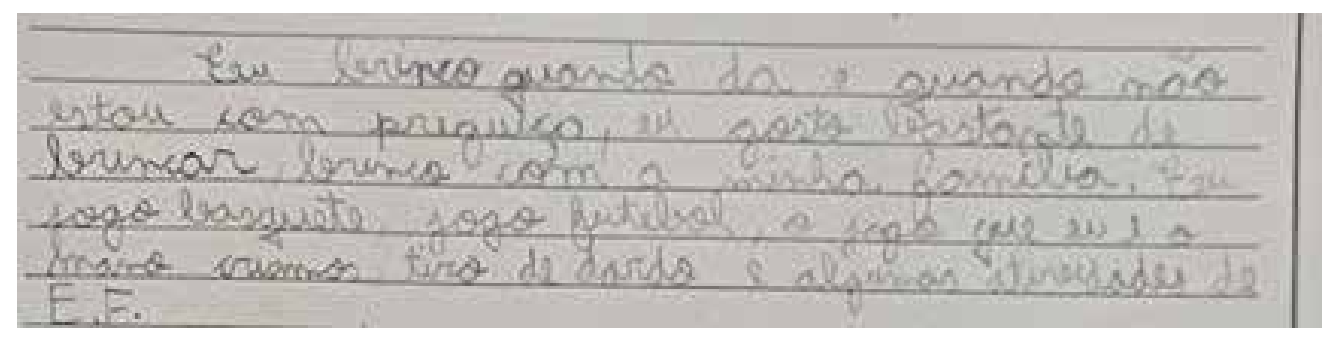

Figura 3 - Narrativa da Criança 13.

Fonte: Dados da pesquisa (2020).

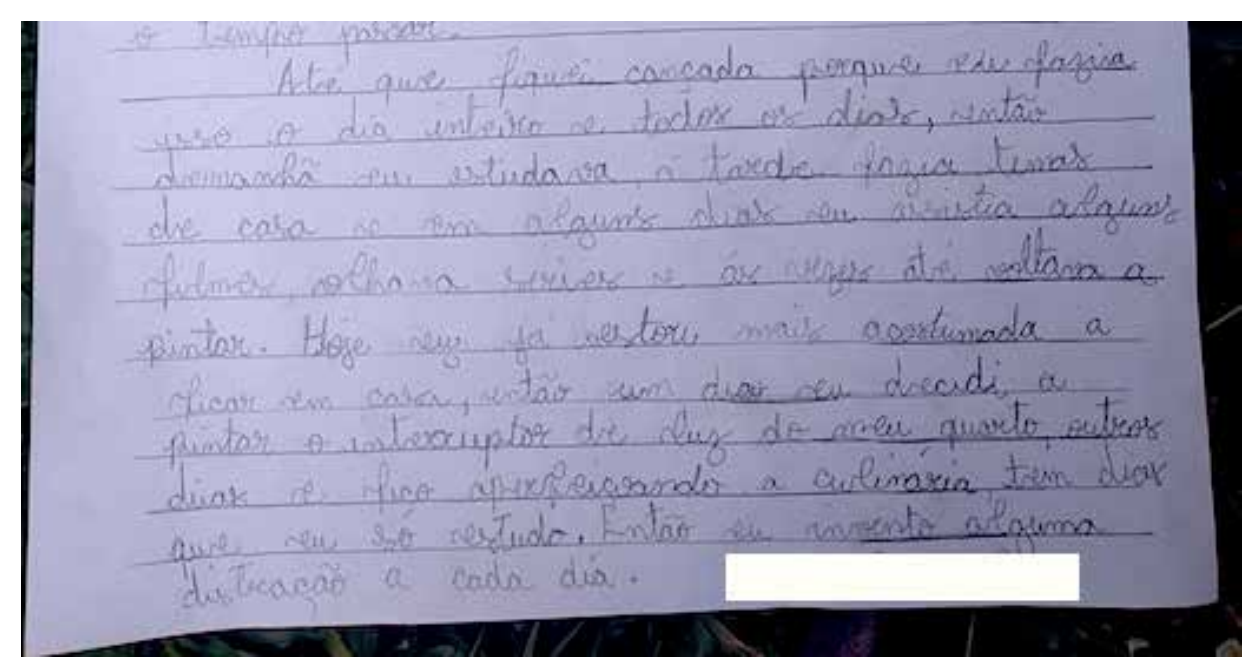

Figura 4 - Narrativa da Criança 11. Fonte: Dados da pesquisa (2020).

Parece-nos que, dependendo da idade da criança, a brincadeira encontra outro lugar, o lugar da preguiça, do tédio, de algo que, de certa forma, está sendo substituído pelo uso das tecnologias, bem como pelas repetições impostas por essa nova rotina, como descreve a narrativa da Criança 11: "eu fazia isso o dia inteiro e todos os dias".

Mas também tivemos muitos registros de brincadeiras em casa, ao ar livre, e da participação da família e dos animais de estimação, que foram inclusive mencionados em quatro narrativas. Dentre as mais recorrentes, percebemos que as brincadeiras tidas como mais tradicionais, como boneca, comidinha, jogar bola, andar de bicicleta e dançar, ainda são presentes nas rotinas infantis. Novas cenas do cotidiano familiar, como "brincar de escritório" (Criança 6), também ganham espaço ao lado de cenas clássicas como "brincar de casinha" (Crianças 5 e 6). Diante de um novo cenário de home office, é interessante perceber, no imaginário infantil, novas representações através do brincar: "Toda brincadeira começa com uma referência a algo que existe de verdade. Depois, essa realidade é transformada para ganhar outro significado". (BROUGÈRE, 1997, p. 41). Por outro lado, tais brincadeiras dividem espaço com tecnologias como jogos de videogame, celular, 
televisão e até o próprio canal do Youtube - mantido pela Criança 13. Além disso, apareceram também as brincadeiras que remetem ao espaço escolar, como desenhar, escrever, pintar e ler.

Podemos dizer que "A relação particular que as crianças estabelecem com a linguagem, através da aquisição e aprendizagem dos códigos que plasmam e configuram o real, e da sua utilização criativa, constitui a base da especificidade das culturas infantis". (SARMENTO, 2003, p. 04). A partir de Sarmento, percebemos que as crianças estabelecem múltiplas linguagens também neste período de distanciamento social. Na próxima seção, adentraremos alguns dilemas contemporâneos que emergiram nas narrativas.

\section{"Vai passar": dilemas contemporâneos das crianças}

Neste segundo grupo de sentido, trazemos, a partir das narrativas, os novos dilemas que assolam o cotidiano das crianças neste momento, tais como: brincar sozinho, ter medo de se contaminar, e acreditar que "vai passar". Para tais análises, acreditamos que

[...] é preciso assumir as crianças, independente da idade, como seres sociais competentes e dotados de emoções e sentimentos à luz das suas próprias evidências, ou seja, que participam ativamente nos processos de transformação das regras sociais, como atores sociais, com o mesmo estatuto de outro ser social (FERREIRA, 2005, p. 131).

As crianças jamais estiveram imunes aos momentos históricos, mas foi essa mudança paradigmática de olhar para as crianças que a Sociologia da Infância, no nosso caso, oportunizou-nos ao nos permitir olhar para elas como atores sociais que têm muito a dizer sobre suas vidas. Falar sobre uma cultura da infância significa dar valor às capacidades e potencialidades de uma imagem de infância capaz de escapar de predeterminismos e determinações. (HOYUELOS, 2019).

As crianças que participaram da pesquisa sabem o momento delicado que estamos vivendo, de modo que esses novos protocolos de vida impostos, como o distanciamento social, estão marcados em suas escritas. Na narrativa da Criança 11, ela registra: "estou consciente que tudo isso vai passar, mas precisamos fazer a nossa parte”. 


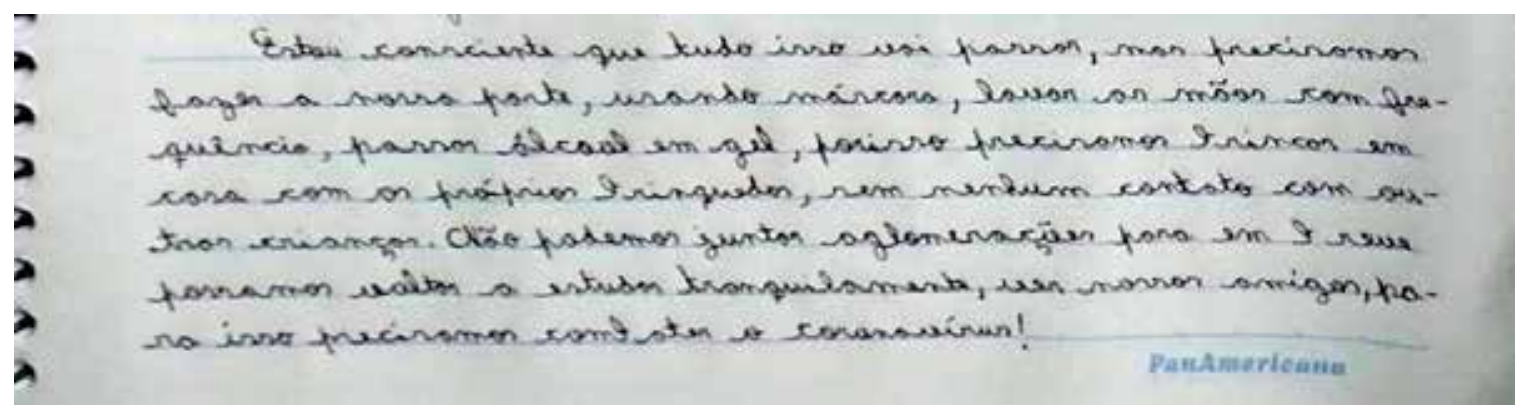

Figura 5 - Narrativa da Criança 11.

Fonte: Dados da pesquisa (2020).

Mas "fazer a nossa parte" não tira a complexidade que é intrínseca a essa ação, como observamos na próxima narrativa.

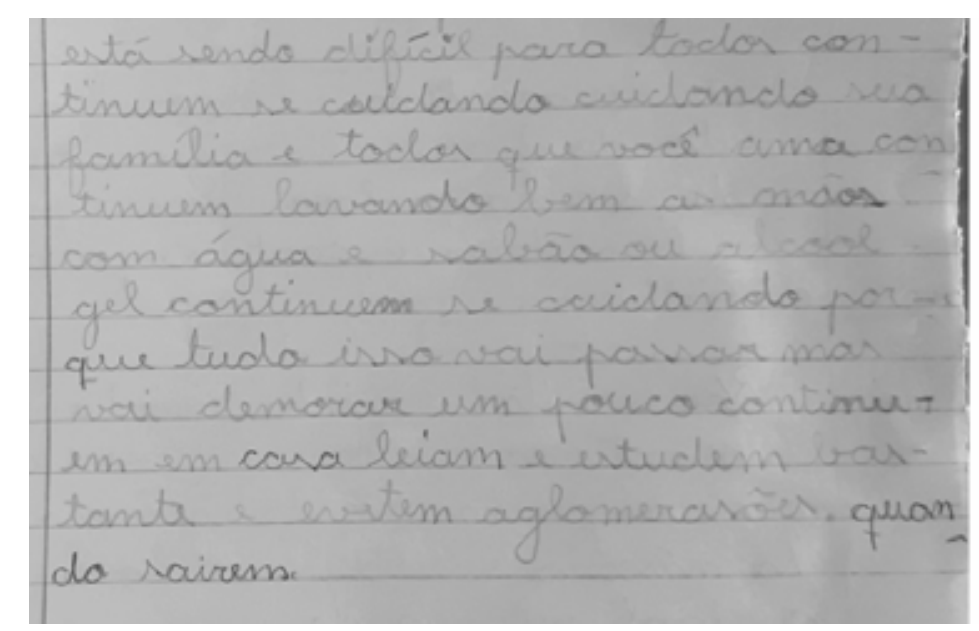

Figura 6: Narrativa da Criança 4. Fonte: Dados da pesquisa (2020).

O que está posto nessas duas narrativas tem a ver com as suas próprias representações de mundo. Conforme Corsaro, "As culturas da infância, vivem do vai-e-vem das suas próprias representações do mundo geradas nas interações entre os pares, nos jogos, nas brincadeiras e no uso das suas próprias capacidades expressivas (verbais, gestuais, plásticas)”. (CORSARO, 1997, p. 26 - nossa tradução).

Não estar entre seus pares é um problema que essa geração de crianças está vivenciando e que, em nossa opinião, pode ter efeitos nos modos de brincar futuramente. Acreditamos que, em especial, as crianças não sairão ilesas deste momento que estamos vivendo, o que impactará no seu direito à brincadeira. Ao brincar, a criança gera um novo repertório de cultura, de expressões, de resolução de problemas e de entendimento do mundo. Ao encontro disso, Huizinga (1987) já sinalizava o quanto a brincadeira é mais antiga que a cultura, ao mesmo tempo em que ajuda a construí-la. 
Cabe aos adultos, professores e pais, manter a valorização do brincar, contribuindo para a organização de espaços e tempos para essa atividade. Compreendemos que a organização de um espaço próprio do brincar tem contribuições significativas na aprendizagem das crianças. Ao situá-las como atores sociais que produzem suas próprias culturas infantis enquanto contribuem para a construção da sociedade dos adultos, os espaços e tempos permitem esse movimento. Trazemos ainda a importância de registrar que o brincar também se dá sem brinquedos, através de brincadeiras simbólicas que exploram a linguagem, a imaginação. Seria o "brincar livre", no qual, segundo Piorski, "[...] é possível encontrar a alma da criança. Nesses brinquedos e em sua materialidade, há um espaço imaterial que, na verdade, é o cerne". (PIORSKI, 2016, p. 21).

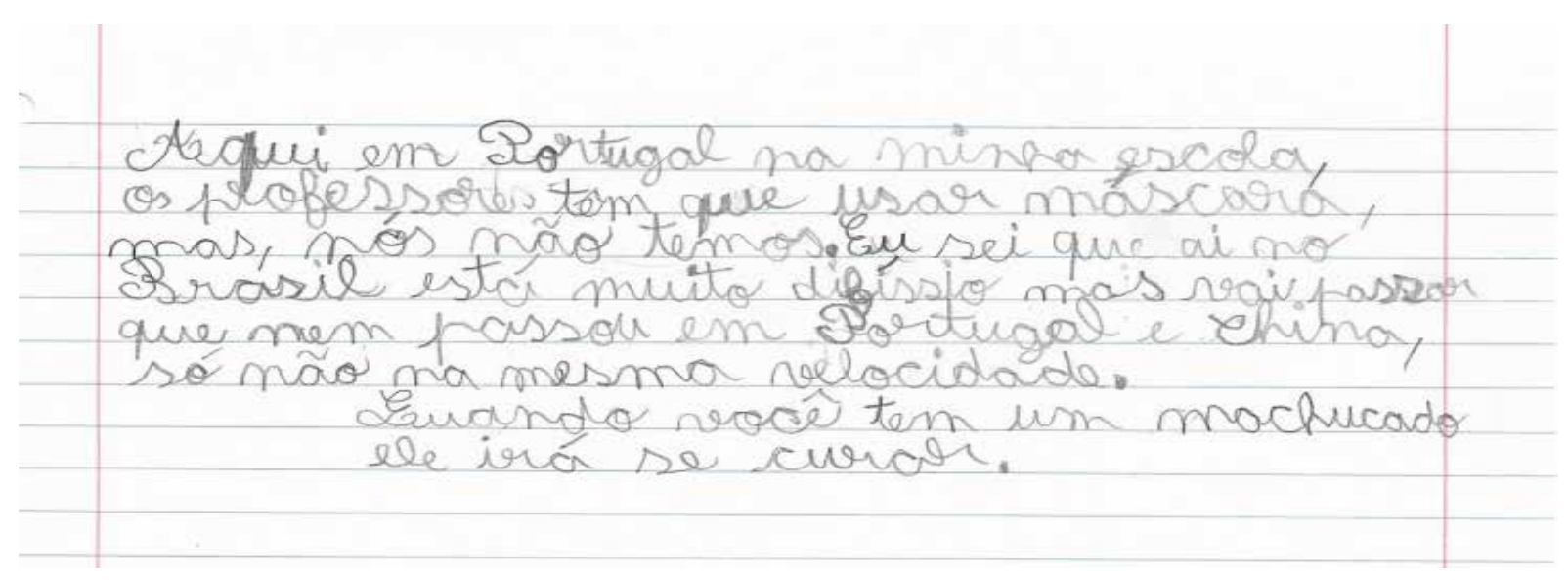

Figura 7 - Narrativa da Criança 9. Fonte: Dados da pesquisa (2020).

Encerramos esta seção a partir da narrativa da Criança 9, que nos enche de entusiasmo. Trata-se de um menino de Portugal que teve acesso à pesquisa por meio das redes sociais. Ainda que sua narrativa não tenha se dedicado a escrever sobre o brincar, trouxe-nos um alento para seguirmos firmes. Já dizia Sarmento: “A criança torna a vida uma aventura continuamente reinvestida de possibilidade. (SARMENTO, 2003, p. 63).

\section{Considerações finais: o que aprendemos com as narrativas das crianças?}

Brincar não é, portanto, exclusivo das crianças, é próprio do homem e uma das suas actividades sociais mais significativas. Uma diferença importante, porém, é que as crianças brincam, continua e devotadamente e, ao contrário dos adultos, entre brincar e fazer 
coisas sérias (entre o ócio e o negócio ou entre o lazer e o trabalho) não fazem distinção, sendo o brincar muito do que as crianças fazem de mais sério. (SARMENTO, 2003, p. 12).

Reconhecemos que falar de infâncias é algo muito complexo; consequentemente, "lê-las" é algo maior ainda. Qualquer aparente descrição que tenhamos feito diante de suas narrativas será sempre uma interpretação, um relato e uma narração também nossa - portanto, compartilhada.

Neste texto, apresentamos, por meio das narrativas escritas pelas treze crianças participantes do estudo, seus posicionamentos sobre o brincar em tempos de distanciamento social. A participação efetiva das crianças foi central para o desenvolvimento desta pesquisa, que buscou investigar questões latentes e contemporâneas da sua nova vida cotidiana, bem como observar o apoio recebido dos facilitadores, seus responsáveis.

Muitos foram os apontamentos trazidos pelas crianças, e muitos serão os desafios a serem enfrentados por elas nestes tempos de pandemia, uma vez que ainda não existe previsão de retorno físico/presencial às atividades escolares e às interações sociais. Também não sabemos como será o novo normal daqui para frente, mas nos associamos às Crianças 9, 7, 4 e 11 quando expressam a crença de que tudo isso vai passar.

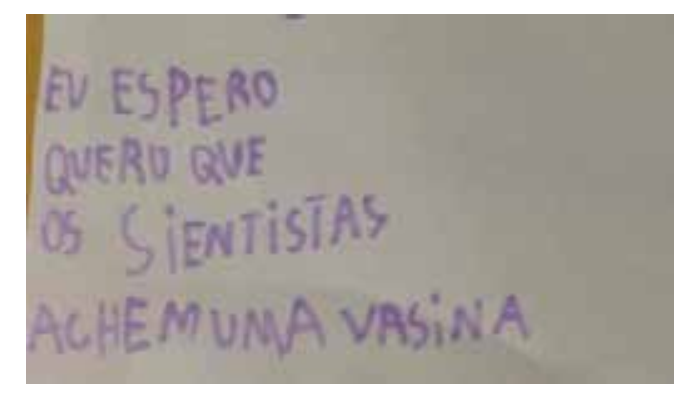

Figura 8 - Narrativa da Criança 7. Fonte: Dados da pesquisa (2020).

Também esperamos por esta vasina. Neste sentido, os dados construídos pelas crianças participantes e por nós, neste texto, propuseram-se a visibilizar as crianças e seus modos de brincar, mas principalmente os seus modos de viver neste momento de distanciamento social.

A Sociologia da Infância, enquanto viés teórico-reflexivo, proporcionou, nesta análise, muitas contribuições, como a valoração da participação das crianças como sujeitos competentes, além de outro olhar, que parte também da criança e não apenas recai sobre ela, tal como vimos nas narrativas que integram este estudo. Como escreveu Sarmento, 
O que aqui se visibiliza neste processo é que as crianças são competentes e têm capacidade de formularem interpretações da sociedade, do e de si próprios, da natureza, dos pensamentos e dos sentimentos, de o fazerem de modo distinto e de usarem para lidarem com tudo o que as rodeia. (SARMENTO, 2007, p. 26).

A pesquisa deixa como legado essa consciência de cuidados consigo e com os outros expressos pelas crianças, bem como a percepção, considerando suas narrativas, de que o tempo do brincar, seja ele livre, com a família ou mesmo de modo contemplativo, estará sempre presente, ainda que de modos diferenciados dos usuais, buscando um espaço de sutileza, da brisa poética, ética e estética, como dito por Machado: "Apropriar-se desse tempo é um direito de cada criança no mundo. Inserir essa temporalidade é dever do adulto". (MACHADO, 2004, p. 31). Por fim, o entrecruzamento de diferentes narrativas infantis nos possibilitou importantes reflexões, permitindo-nos finalizarmos este texto com mais vigor e rigor para mantermos em nossas agendas de pesquisa as questões do brincar na vida das crianças.

\section{Referências}

ALMEIDA, Ana Nunes de. Para uma sociologia da infância: jogos de olhares, pistas para a investigação. Lisboa: Instituto de Ciências Sociais, 2009.

BRASIL. Promulga a Convenção sobre os Direitos da Criança. Decreto n. 99.710, de 21 de novembro de 1990. Disponível em: http://www.planalto.gov.br/ccivil_03/decreto/1990-1994/d99710.htm. Acesso em: 12 ago. 2020.

BRASIL. Resolução no 510 , de 7 de abril de 2016. Conselho Nacional de Saúde. Disponível em: http://www. in.gov.br/materia/-/asset_publisher/KujrwoTZC2Mb/ content/id/22917581. Acesso em: 13 jul. 2020.

BARBOSA, Maria Carmem Silveira, DELGADO, Ana Cristina, TOMÁS, Catarina. Estudos da infância, estudos da criança: quais campos? quais teorias? quais questões? quais métodos? Revista Inter Ação, v. 41. n. 1, p. 103122, 2016.

BRUNER, Jerome. Realidade mental, mundos possíveis. Porto Alegre: Artmed, 2002.

BROUGÈRE, Gilles. Brinquedo e cultura. São Paulo: Cortez, 1997. 
CORSARO, William. The sociology of childhood. London: Pine Forge, 1997.

FERNANDES, Natália. Infância, Direitos e Participação: Representação, Práticas e Poderes. Porto: Afrontamento, 2009.

FERNANDES, Natália. Infância. Ética na Pesquisa com crianças: ausências e desafios. Revista Brasileira de Educação, v. 21, n. 66. p. 759-779, jul.-set. 2016.

FERREIRA, Manuela. Brincar às Arrumações, Arrumando ou... entre a ordem institucional adulta e a ordem instituinte infantil, as crianças como actores sociais no jardim da infância. Reflexão e ação, v. 13, n. 1, p. 115-132, 2005.

HUIZINGA, Johan. Homo ludens. Madrid: Alianza, 1987.

HOYUELOS, Alfredo. Cultura da infância e âmbitos da brincadeira. In: HOYUELOS, Alfredo: RIERA, Maria Antonia. Complexidade e relações na educação infantil. São Paulo: Phorte, 2019. p. 149-173.

KISHOMOTO, Tizuko Morchida. Brinquedos e brincadeiras na educação infantil do Brasil. Cadernos de Educação de Infância, n. 90, p. 4-7, 2010.

LIMA, Samantha Dias de. Narrativas escritas: o que "narram" as formandas de Pedagogia sobre suas aprendizagens acerca das infâncias durante a graduação. Reflexão e Ação, v. 25, n. 3, p. 237-255, set. 2017.

LIMA, Samantha Dias de. Pedagogias, infâncias e docências: o que narram as acadêmicas sobre suas aprendizagens? Revista Educação em Foco, v. 21, n. 33, p. 13-34. jan./abr. 2018.

LIMA, Samantha Dias de. Tecnologias Digitais de Informação e Comunicação como estratégia pedagógica: um olhar sobre a experiência de um curso de Pedagogia em tempos de pandemia. Revista Olhar de Professor, v. 23, 2020. (no prelo)

MACHADO, Maria Marcondes. A poética do brincar. São Paulo: Edições Loyola, 2004.

PIORSKI, Gandhy. Brinquedos do Chão: a natureza, o imaginário e o brincar. São Paulo: Peirópolis, 2016.

SARMENTO, M.; GOUVEA, M. C. S. (Org.) Estudos da Infância: educação e práticas sociais. Petrópolis: Vozes, 2009. 
SARMENTO, Manuel Jacinto e PINTO, Manuel. As crianças: contextos e identidades. Braga, Portugal, Coleção Infans, Centro de Estudos da Criança, Universidade do Minho, 1997.

SARMENTO, Manuel J. Imaginário e culturas infantis. Cadernos de Educação, v. 21, p. 51-59, jul./dez. 2003.

SARMENTO, Manuel Jacinto. Gerações e alteridade: Interrogações a partir da Sociologia da Infância (p.361-378). Educação e Sociedade, v. 26, n. 91, p. 361-378, maio/ ago, 2005.

SARMENTO, Manuel Jacinto. Culturas infantis e interculturalidade. In: DORNELLES, Leni Vieira (org.). Produzindo pedagogias interculturais na infância. Petrópolis: Vozes, 2007.

TOMÁS, Catarina. Há muitos mundos no mundo: cosmopolitismo, participação e direitos da criança. Porto: Afrontamento, 2011. 